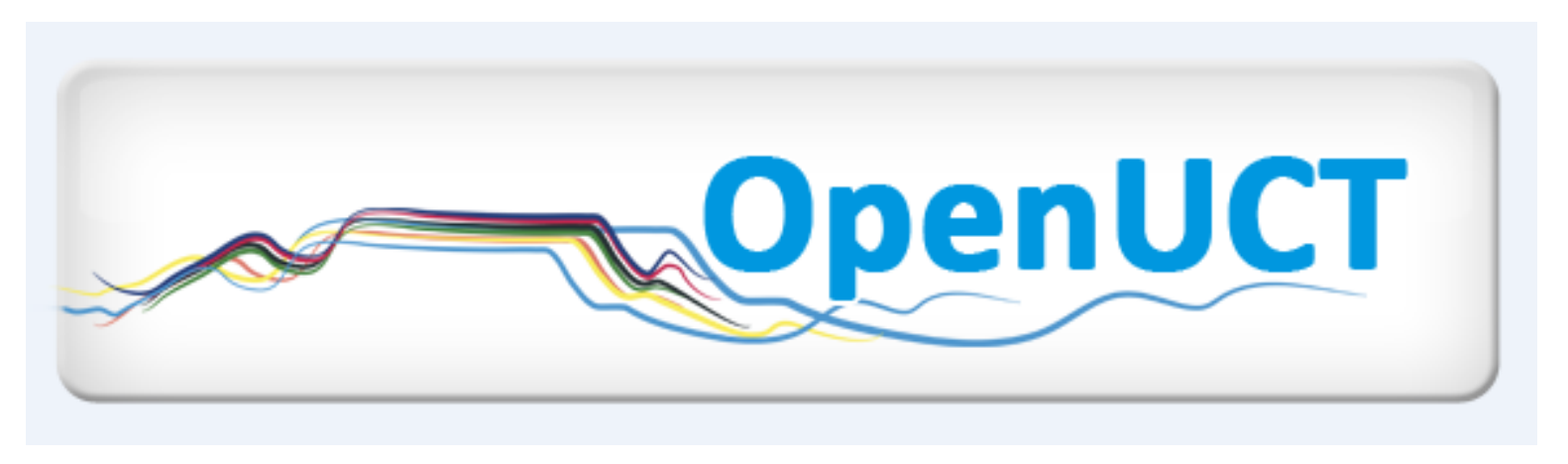

This is the post-print of Pym, J. \& Kapp, R. 2013. Harnessing agency: towards a learning model for undergraduate students. Studies in Higher Education. 38(2): 272-284. DOI:10.1080/03075079.2011.582096.

It is made available according to the terms of agreement between the author and the journal, and in accordance with UCT's open access policy available:

http://www.openuct.uct.ac.za/sites/default/files/UCTOpenAccessPolicy.pdf, for the purposes of research, teaching and private study. 


\title{
Harnessing agency: towards a learning model for undergraduate students
}

\author{
June Pyma and Rochelle Kapp
}

\begin{abstract}
This article describes a successful academic development programme in a Commerce faculty at a relatively elite, historically white university in South Africa. The writers argue that the programme has managed to achieve good results in recent years by moving away from deficit models of academic development for students from disadvantaged backgrounds. The article draws on five years of data to illustrate how students' home discourses have influenced their negotiations of institutional discourses. It is argued that many of the students have shown considerable agency in gaining admission to university despite their social backgrounds, but experience a crisis of confidence and self-esteem in the new environment. The article describes how the new model of academic development has responded to this context by providing a more flexible approach to the curriculum, which attempts to harness students' agency as well as foster a sense of belonging to a learning community. Also described are the range of interventions that have been put in place specifically to develop a culture of learning and to promote social connectedness, identity and agency.
\end{abstract}

Keywords: academic development model, disadvantage, identity||agency, undergraduate

\section{Introduction}

Policies of widening access in Higher Education sectors around the world have meant an increase in numbers of students who enter into the institution without the "cultural capital" (Bourdieu 1991: 230) deemed necessary by higher education institutions. Once they gain entry, these students often have to cope with multiple academic, linguistic and social and challenges that will impact on their studies (Swail 2002 and Mann 2008). There is increasing pressure for higher education institutions to engage with different levels of disadvantage in the learning environment. Nevertheless, by and large, institutions still tend to construct students' home identities and languages as a problem that has to be fixed through the provision of quick-fix support skills courses (Rose 1990; Haggis 2006 and Mann 2008). This paper describes and theorizes a teaching and learning model in the South African context which has reversed a record of student failure by challenging such assimilationist, deficit notions of the teaching and learning process.

In the post-Apartheid era, the South African Higher Education sector has remained racially skewed. Research by Scott et al (2007) analyses the total 2005 higher education enrolment and reports a five-fold difference between the gross participation rates of white (60\%) and black (12\%) 20-24 age-groups. Based on the 2000 intake into Higher Education, the study shows that only $38 \%$ of all first-time entering students graduated within five years. In general, efforts to redress the imbalances caused by the Apartheid system have focussed on the structural factors that act as a barrier to success. These include issues such as poor teaching at the school-level; lack of articulation between school and university; difficulties with the medium of instruction; poor career guidance and lack of bursary support. Designated funding has been set aside to address these issues, and most higher education 
institutions have established Academic Development (AD) programmes ${ }^{1}$ which cater for students who are admitted under special conditions on the basis of equity ${ }^{2}$ considerations.

These programmes have addressed the academic and linguistic difficulties by putting in place structured courses to compensate for the deficit of schooling. The notion has been that the content gaps of schooling have to be filled and students have to be taught ways of thinking, problem-solving, reading and writing that challenge the formula-driven, rote-learning modes that characterize many black working-class and rural schools. Typically, students who have not met the required entry criteria are placed on these programmes. They are provided with extra courses in small, separate, compulsory first-year programmes taught by specialised staff and thereafter, exit into the mainstream programmes to continue with their studies. The need to counter the stigma associated with special programmes for black students at historically white institutions has meant that there has often been an avoidance of a direct focus on the socio-cultural and psychological aspects of students' transitions into higher education for fear of pathologizing black student experiences and creating a notion of victimhood.

Ironically, the history of AD has in many ways exacerbated students' experience of being 'other' and marginalised in the university as students' identities have been constructed as being 'less able' and 'ill prepared'. A deficit assumption (Boughey 2010) has predominated, focusing on students' lack of preparation to cope with tertiary studies. These stereotypes have been compounded by the politics of race and class in South Africa. The silence about the psychological and social aspects of the transition ignores the considerable identity challenges faced by young black students who have come from impoverished conditions and often dysfunctional homes and schools into relatively elite universities (see also Marshall and Case 2010). Instead, there has been a strong emphasis on assimilating students into higher education with a concomitant "cultural literacy" model (Knoblauch and Brannon 1984: 29) foregrounding middle class, white, Anglicised norms and values. By their very nature, such programmes often have the unintended effect of producing what Steele (1999: 44) calls "stereotype threat", that is, an overarching anxiety that becomes a self-fulfilling prophecy. The consequence is to encourage passivity and dependence, thus stripping students of the agency which enabled them to attain access to tertiary studies despite their home and school circumstances.

This paper describes a successful Academic Development programme in the Commerce Faculty at the University of Cape Town which has managed to achieve good results in recent years by moving to a more flexible approach, adding value to

\footnotetext{
${ }^{1}$ Mainly as a consequence of the racially skewed educational system, Academic Development in South Africa is focused on strategies and programmes that address student needs. While training and development of academics is generally part of the brief, it is not the main focus as in the United Kingdom for example.

${ }^{2}$ Generic term to be used for all previously disenfranchised people in South Africa
} 
the curriculum and student experience, while attempting to harness students' agency as well as foster a sense of belonging to a learning community.

\section{Theoretical Framework}

The model draws on experience of working in this context, and a growing body of educational theory which has shown that identity is central to learning. Recent poststructuralist theory has emphasized the complex interplay of structure and agency in the educational process. While Gee (1990: 142) argues that the accepted ways of "saying-doing-being-valuing-believing", i.e. discourses that characterize home and institutional contexts are powerful socializing agents which require individuals to take up subject positions within their ideological framework, a range of critics have produced less totalizing accounts which argue that individuals can and do act within these frameworks, that individual lives are both "constrained" and "agentic" (Thomson 2009: 154). Here, agency is understood as an individual's capacity to act purposively to make choices about how they wish to live and to act upon those choices (Walker 2006). In this reasoning, educational success and failure are influenced by "structures of opportunity" as well as individual motivation, effort and ability to reflect at a meta-level (Christie 2008: 8; see also Luckett and Luckett 2009).

Theorists like Norton (1997) and Thomson (2009: 160) have used the notion of "investment" to understand when, where and why individuals engage (or disengage) with "socially and discursively available resources". They have argued that motivation to learn is context dependent and often contradictory. Individuals invest in certain subject positions rather than others at particular times in relation to structures of power and opportunity. They negotiate who they are and who they want to be in relation to past and present interaction and importantly, in relation to "the desire for recognition, the desire for affiliation, and the desire for security and safety" (Norton 1997: 410). Post-structuralist theorists on identity have argued that it is crucial to recognize and take individuals' past identities and literacies into account as they encounter new discourses.

The new discourses that students encounter as they enter into the academy are embedded in taken-for-granted ideological frameworks and the boundary lines that connote inclusion or exclusion are often obscure. Students have to learn to negotiate norms, values, attitudes and beliefs different from their home discourses both within the institution and within their disciplines. This process often produces considerable conflict and ambivalence. This emotion-work is invisible, and yet requires considerable symbolic resources.

Thus, we argue that an enabling learning programme should be transparent and unapologetic about the need to provide appropriate academic structures for students who are academically under-prepared as a consequence of poor schooling. However, such provision should find ways of connecting to students' home identities, should cater for individual learning needs and strengths, and should foster students' investment in their learning and sense of belonging within the institution. 
This paper starts with a description of the institutional context and then describes how students have constructed themselves as learners within their home and school settings. This description is informed by data collected over a five-year period (2005-2010) and consists of 720 questionnaires which students complete on arrival, student evaluations as well as 31 individual semi-structured interviews of first-year students. These data are used to illustrate how students' home discourses have influenced their negotiations of institutional discourses. We then proceed to show how the Commerce AD model attempts to address students' academic needs and foster agency.

\section{The institutional context}

The University of Cape Town is a historically white university and is regarded as one of the most elite universities in South Africa. Academic access to the institution is difficult and only students who have excelled in their formal school examinations are considered for admission. The Commerce Faculty is viewed as prestigious in terms of academic results and its international professional credibility. It has one of the highest entry grade requirements in the university. While the student composition has shifted so that Commerce has 47\% equity students (2009 UCT enrollment data), the academic staff composition of the faculty is $59 \%$ white (Institutional Planning Department 2009). The majority of students who complete a B Com degree are registered for the Chartered Accounting programme. Only 16\% of Chartered Accountants in South Africa are black (The South African Institute of Chartered Accounting 2009: 12) which gives some indication regarding both the historical backlog of the legacy of apartheid, as well as the serious competitiveness in this field. There is very strong political and professional will within the faculty to shift this alarming profile and focus on seeking out the brightest and best black students.

\section{Who are the first year AD students?}

The AD programme has approximately 750 students in total and an average of 250 first year students are accepted into the programme (Bachelor of Commerce and Bachelor of Business Science degrees) each year. The AD programme makes up approximately $31 \%$ of the Commerce Faculty's black students. The majority of these students would have been educated at rural and working-class schools, with English as an additional language and most are the first generation in their families to attend university.

Many of the students come from desperate and impoverished families. Many either do not know their fathers or have very limited contact with them. The following example is typical:

I was raised by my strong and powerful mother. I have experienced a lot of violence in my youth leaving me to grow up quickly and see the world with sceptical eyes or view. I have gone through life not having a father figure this 
causing me to resent men or families with fathers and I also became cold and resilient - focused on my books and passing better than most people.

Students' paths through school have often been marked by considerable agency with students taking adult decisions at an early age. Many have developed quite sophisticated coping mechanisms in negotiating trying family and school circumstances and have often worked independently to achieve their results. For example: "I lost both my parents at a young age, I had to live with a family relative who did not treat me very well and that motivated me to put more effort to my schoolwork". As a consequence of splintered family life, academic success has sometimes been the only viable direction to take. A student from the 2008 cohort says: "I grew up with my grandmother - she died when I was in grade 9 and I had nowhere to go. Luckily I applied to the Cape Academy for Maths and Science and received a bursary ... the school has taught me how to be independent and disciplined".

\section{Negotiating the transition}

Whatever the students' circumstances, their identities have been affirmed in the past by the fact that they have excelled in their schooling contexts. They arrive at the university fairly confident with an identity that has been developed around being an achiever. For example: "In my village not so many people are educated in such a way that I am the first person in my family and in my village to be in a prominent university...". Students' sense of optimism is often fuelled by particular religious convictions. This discourse seems to act as a "sponsor" for their actions by offering a social identity which facilitates security, connection and agency (Herrington and Curtis 2000: 369). For example: "What I am is a gift from God and what I become is a gift to God" ; "I've gone through so much in life, nobody understands the trials and tribulations I've been through but through God l've overcome most of them" and "I love God, just madly" and "I get a lot of my strength from God and he's the sole person I put all my trust in".

Many of the students' narratives express strong dreams for themselves and for their potential contribution to their families and communities: "I would like to obtain my degree and become a valuable citizen in the upliftment of my community"; "I am an optimist and have a very bright future ahead of me" ; "I want to go somewhere with my life" ; "I hope to inspire others and give back to the masses of the African people. I want to be a beacon of hope and triumph to all!!" and "There are many dreams I still have ahead for my life and I strongly believe and know that through the education and knowledge l'll receive in this place I will achieve".

As a consequence of their backgrounds, students often register for their Commerce degrees for instrumental reasons and not necessarily because of a considered career choice. A strong motivation is the power of the degree to open a space for employment and social and geographic mobility. For example, "I want to be a successful Chartered Accountant in the near future and help my parents out of the difficult financial situations they find themselves in" and "Education is the only 
way you will get yourself out of this place" (referring to her impoverished living situation).

For many, the experience of arriving at the university is liberating and exciting in that the institution is well resourced, feels relatively safe, offers freedom of movement and the possibility of new experiences and relationships. A student relates a positive experience as "meeting my new and very diverse group of friends that will hopefully last me a lifetime"; another student speaks about "being able to make my own decisions in terms of what to do and when to do it has been a very crucial part of my personal growth".

Nevertheless, many students experience a crisis that relates both to academic and linguistic difficulties and to affective issues. Many of the academic difficulties that these working-class and rural students experience are similar to those experienced by mainstream Commerce students in that they have mostly not been prepared for higher education demands of independent study or for analytical engagement at cognitively demanding levels. On the whole, large classes are usually lecture-centered and the anonymity provided often militates against promoting students' involvement and intellectual development (MacGregor et al 2000). However, the comments by the students in our study about their transition also bear the quite specific imprint of Apartheid schooling. The majority of black working-class and rural students are still educated in print-impoverished, underresourced environments, often characterised by teacher-centred, predominantly oral classroom cultures. In a context where close to 90 percent of students study through the medium of English (their second or third language), school teachers often compensate for their own and students' struggles in the language by teaching in students' home languages. Nevertheless, their texts are written in English and students have to pass examinations in that language. There is little close engagement with texts and limited analysis of concepts. Literacy practices are dominated by rote-learning and take on an instrumental character, functional to the externally set examinations that students have to pass in order to gain a schoolleaving (matriculation) certificate (Slonimsky and Shalem 2004; Kapp 2004 and Christie 2008). While it seems that the students in our study have learnt to take responsibility for their learning in a context where teachers are often absent and where the culture of teaching and learning is often not conducive to learning, their school environments have not prepared them to cope with the level of cognitive academic language proficiency (Cummins 1996) and the pace of engagement in the new environment. As one student says: "I'm finding it difficult to understand ... very fast and strictly in English". Many students are self-conscious about their level of English and are intimidated and unable to ask questions. The following quotation highlights the meta-level shift that students have to make in terms of approach to learning and cognition:

Varsity, the pace and the way you do things is completely different to school ....". "I think maybe it's also the way it was taught and, because some of the things they assume that you know from school and sometimes you haven't covered those things so you have to go 
and actually re-teach it to yourself and the standard, they assume that you know a lot more than sometimes you do, and it requires much more time and practice than in high school". "I can't just sit and read some of the things, like I used to have ways of remembering, making up little sayings and things and some of the work now it's hard to still do those things because it's much more to remember. ... in school you have to learn to remember, here you have to learn to know .

Time is also an issue because the pre-programmed structures and spoon-feeding practices of school have not prepared students to cope with multiple demands simultaneously. This often results in students spending inordinate amounts of time with their studies to the exclusion of other activities, or becoming so overwhelmed that little gets done and the ripple effect is one of feeling "out of control": "Adapting to university and time management. Struggling to stay focused because I am always tired, stressed and overworked. Balancing the time I allocate to courses as I neglect the ones I am not good at".

A significant number of the students experience varying levels of demoralisation and loss of self-acceptance when they first realise that their schooling has not prepared them for university. A student, speaks about how she is constantly comparing herself ".. to other people and then you feel inadequate and then I start thinking the people around me are so smart and I'm not". Another student finds it very difficult "Seeing that everybody is coping even though I do not understand what is being said".

In some cases, the fraught conditions of home continue to make demands and affect students' ability to focus. A significant number of students speak of missing home and experience loneliness and isolation as they attempt to make connections within a new environment where they know no-one: "Because I've been living away from my friends and my family and I have to kind of find myself away from all, find out who I am away from all those things that used to define me, ja" . For some students, isolation through study has become a way of seeking refuge from difficult home conditions: "I had to move out of my stepfather's house when my mother died and move to my aunt. The experiences I had while I was under her roof would not be music to anyone's ears but such experiences I am grateful for, for they made me fall in love with my books and be my own best friend".

Diminished self-acceptance seems to affect students' ability to connect with others. Their eroded self-esteem often leaves them feeling unworthy and there are a large number of students who indicate how they battle with socializing and selfconfidence: "My own true enemy is confidence" ; "I am intelligent and have always been at the top of my class but despite it all I am not that high on self confidence" ; "I'm not really self-confident and I still loathe myself to a certain extent"; "I am a shy girl and my lack of confidence is sometime a problem for me"; "I was taught at a very young age that when people speak, I should keep silent and listen" and "..what I have gone through in my life (that I cannot talk about) made me a reserved child who doesn't want to be more exposed to others for they might hurt me as always" . 
Recent student experience research pertaining to the international context (see Herrington and Curtis 2000; Reay 2001, Reid et al 2003; Christie et al 2008 and Mann 2008 for example) has shown that experiences of alienation are fairly common for all students, but particularly so for many first generation students as they enter into the middle-class environment of higher education. However, the dislocation of conventional family structures, the breakdown of the culture of learning and teaching in schools, the violence and conflict in the society has meant that black workingclass and rural learners in South Africa are placed in situations of extreme risk and vulnerability (see Ramphele 2002; Bloch 2009 and Bray et al 2010). Ironically, these young people are simultaneously being offered unheard of opportunities and possibilities of rapid upward mobility. For many students higher education is seen as an escape, a route out of their impoverished home circumstances. Nevertheless, entering into a new environment where very little is familiar and which is physically far from home often produces intense loneliness and a loss of voice, self-esteem and purpose. It is clear from the data that the academic and psychological issues are intertwined. In Luckett and Luckett's (2009: 480) words, "preparing cohorts of professionals [in the new South African context]... entails negotiating shifts in consciousness, identity and modes of reflexivity related to severe contextual discontinuity". We believe that development of social connectedness, identity and agency strongly assists academic success. It also contributes to the broader development of critical citizenship and social responsiveness. In the next section, we outline the model that has been developed to address this context.

\section{Harnessing Agency}

In the past, the $A D$ work focused exclusively on the academic unpreparedness of first year students to cope with a Commerce degree. Students were placed on the programme if they had not met the required academic school results to gain access to the faculty. Students were conscious of this, did not want to be on the programme and were embarrassed to acknowledge their academic development status to anyone outside of the programme. Students' experiences in AD probably contributed toward further alienation from the 'mainstream' and their sense of belonging at the university because being in a separate programme probably fostered the marginalization already experienced by students. While students tended to pass the academic development courses, they were likely to fail once they re-entered the mainstream.

The changes that have taken place in our model have been gradual and have been the result of ongoing critical review and our research on the challenges faced by students. At a structural level, we agreed that there is a need to retain a separate structure that provides specialised support because, as Bertram (2003) argues, equity of access is not enough to ensure equity of outcomes. In a society that still bears the scars of discrimination, treating students the same has the potential to reinforce inequality as implicitly, those who have acquired the linguistic, social and cultural competencies of the discourse are favoured (Bernstein 1990). We also 
agreed that some form of academic and psychological support needed to be provided throughout the degree. Nevertheless, the model would need to be more flexible, would need to cater for individual needs and be more conscious of how the status of the programme is promoted in relationship to the faculty ${ }^{3}$. An important initial step was to change the admissions process by creating a variety of access points to the programme. Firstly, opportunities for students to apply to the programme (as distinct from simply being 'placed') were created. Secondly, two large bursary schemes now make it obligatory for their recipients to be part of the programme. The inclusion of a variety of students (rather than simply those who have not met mainstream entrance requirements) has played a significant role in helping to shift the sense of 'stereotype threat' and raising the level regarding the academic demands in the class.

We have catered for academic diversity by creating flexible entry and exit points within the programme. For example, we have developed augmented courses which enable students to complete a first year course over the same duration as a semester course, but with a greater degree of support and varying teaching pedagogies. It is possible that a particular student could be registered for a mixture of augmented and extended courses (which are longer in duration). This caters for individual needs by allowing extra time in a course that is vulnerable, but not impeding the student in a course of strength. While students are mostly in separate small classes in their first year, thereafter they continue their studies as integral members of the Commerce Faculty. The greater curriculum flexibility has also meant that students are better prepared for the level and quantity of work in their second year.

The programme now reflects a Vygotskian (1978) influence insofar as acknowledging the primacy of the social and interactive aspects of learning and the importance of student experience. Lecturers know the students individually at the first-year level and a great deal of learning takes place using small group and collaborative work. In this respect, Kurfiss (1988), Astin (1993), Mazur (1997) and Springer et al (1999) all emphasize that fostering higher-order thinking skills, intellectual development and affective student outcomes are maximised with the greater number of student-student and student-lecturer interactions. There is a strong attempt to articulate with their prior learning rather than to discard their schooling in deficit terms. Students are constructed as active participants and are scaffolded into their disciplines through the use of case studies, annotated texts which mediate conceptual understanding, problem-solving scenarios, problem-based learning, simulations and experiential situations. Students are also encouraged to draw on their home languages as resources for learning.

A cross-disciplinary collaboration among lecturers has helped the development of an explicit meta-language which plays a role in developing students' capacity for

${ }^{3}$ For example, in earlier years, student orientation leaders would walk past the $A D$ offices describing this as a programme for 'black students who didn't make the faculty admission point requirements' 
reflective learning and facilitates transfer of knowledge and skills across disciplines. Reflective learning is emphasised within the discipline and is also the subject of special focus in a compulsory skills course which focuses explicitly on a range of meta-cognitive skills (critical thinking, collaborative learning, language and communication skills, career planning and time/stress management).

A crucial aspect of the programme that has contributed to adding value to students' experiences, has been a much stronger emphasis on working proactively in terms of both academic and psycho-social support. Student development officers work with students as a cohort and on an individual basis. While continually exploring ways to be responsive to students' realities, the programme now asserts a particular knowledge and understanding of the students as a way of both preempting crises and building capacity with the rich diversity and resources in the class. For example, monthly class meetings are held for all cohorts in order to ensure continuity, to identify appropriate interventions and to use role-models to inspire and motivate. Student results are scrutinized very early and on an on-going basis as a way of liaising with vulnerable students to assess and negotiate difficulties prior to possible exclusions. Where necessary, students are referred to a counselling service that is integrated into the programme.

The programme attempts to develop both a supportive social community and a culture of learning. There is a strong emphasis on creating a learning community through provision of academic skills and workshops throughout their degree. The programme also offers a suite of opportunities that attempt to promote social connectedness. Senior students take on roles such as mentoring, tutoring and facilitating the induction programme for new students. The induction program at the beginning of the year for all our new students aims at forging a close social network. A well developed web site, communication network and newsletter enhance contact, and the sharing of news and information. There is also a formal student society which organises a range of functions, including social responsiveness projects. In all these interventions, there is a deliberate attempt to create a sense of belonging to a community which offers a safe space for students to express their fears and anxieties, and also provides coping mechanisms. As a number of theorists have argued, in order to feel invested in their learning, individuals need to feel that they belong (Reay, 2001; Reid et al 2003; Chapman and Pyvis 2006; Christie et al 2008; Bangeni and Kapp 2005 and Thomson 2009).

A yearly awards ceremony acknowledges academic excellence and progress. It also provides a platform for acknowledging students' home discourses via their own dance, music and poetry creations. As Walker (2006: 7) argues, "processes of learning and agentic identity formation are intrinsically connected with the process of recognition. By receiving recognition from (significant) others, one achieves a confident and a positive identity". These occasions are seen as an important part of a process to provide the most conducive teaching and learning environment that focuses on "the interplay between the learner and the way in which learning is facilitated" (Coughlan 2006: 213) taking particular cognisance of providing a fertile environment to maximise students' ability to succeed in Higher Education. 
Alongside Walker (2006) and Adams et al (2006), we believe that the period that a student spends in higher education has the potential to be an important time for selfexploration and for developing the tools and resources for the future. Walker (2006) argues that "experiences in higher education for all students - positive and lifeenhancing, or narrowing horizons and self-belief - will shape their lifelong learner identities and choices". Adams et al (2006: 87) draw on Erikson's theory of psychosocial development to talk about the importance of the period of university study as an "institutionalised moratorium" period in terms of identity development. During this late-adolescent period, students have the potential to experiment with various roles and options, to re-shape the map of their futures. In the process of envisioning a future and developing goals, it is important to provide personal narratives with which students can identify. To this end, there has been an increased engagement with alumni from the programme who have served as role models and provided particular motivation for students to take charge of their lives despite the circumstances they might have to negotiate. This has played an important symbolic role in enabling students to see the potential for alternative subject positions.

The programme acknowledges students' fears and doubts, but also challenges them. We see it as crucial not to romanticise or reify the beliefs, attitudes and ways of behaving that students bring with them which may impede their processes of developing a sense of belonging and of connecting to the new discourses. The programme helps students to see that their social identities are not all-determining in terms of their construction of selves and their future goals. In Walker's (2006: 4) terms "agency is both being and becoming". Our task is to help students to develop meta-awareness of the opportunities in and constraints of their environments. As illustrated, many of the students enter with goals that have been pre-determined for them by their families or by institutional constraints. It is part of our task to help them to work reflexively, to reflect on current priorities and develop future goals that are meaningful to them. They have engaged in agentic ways in the past. We provide them with the time and space to reflect on how and why they have engaged in particular subject positions rather than others and to consider how those roles may or may not change in the future.

\section{Impact}

The new teaching and learning environment has made a significant impact on academic results. First-year results in the academic development programme have outperformed those in 'mainstream' classes for the past five years. While we still have a long way to go in terms of improving performance in the senior years, the graduation rate (approximately $68 \%$ ) is increasing and is far above the national average of $31 \%$ in five years for the Business/Management sector in Higher Education (Scott et al 2007).

Students' evaluation comments on the programme have been positive. Their comments reflect their own meta-awareness that both the quality of the teaching and 
learning environment and the provision of psycho-social support have made a difference. One student speaks of the "care for both academic life and other aspects of our lives" and asserts "I wouldn't want to be anywhere else"; and another states that "[it has] helped me be my own person and more independent". Many students speak of the personal recognition and motivation that they receive from the programme, for example: "there is a pool of dedicated men and women who care about me and my future and who would go to great lengths to see me successful" and ".. they emphasize the fact that there is always hope for a very bad situation". "Being on the EDU has been the turning point in my life ... I feel like a part of a family here". "Some days would be really tough but the words of encouragement they would give us during our class meetings meant a lot. At times I felt like giving up but the support I received from EDU I felt I had to so keep fighting and was encouraged to work harder". The qualitative data suggests that the experiences implicit in the EDU programme have impacted strongly on the students' sense of worth and motivation and has helped energise them to cope within the university environment. "Varsity has made us realise the importance of having support from the EDU family to remind us of our dreams and goals because the journey can sometimes throw you off track". "Being a part of the EDU family has given me a great sense of belonging because all my life I have felt out of place" .

A proactive approach has meant a gradual shift in students' taking far greater individual and collective ownership for their learning and their experiences in Higher Education. The organisation has been very active, organising forums, speakers and recreational activities.

Although the issue of a separate programme and students' experiences of marginalization in the broader faculty has not disappeared, there is growing reported feedback that students greatly value being in the programme and would not choose to be in mainstream. In recent years, increasing numbers of mainstream students have requested to be moved to the programme.

Perhaps the most important marker of success is that the Commerce Faculty has now established an Education Development unit which has an explicit mandate to draw on the strategies within the Academic Development Unit in order to improve teaching and learning in the 'mainstream'.

\section{Conclusion}

The model has drawn on educational theory on identity in the learning environment and has responded to specific social conditions in South Africa as a way of addressing students' academic needs and developing agency. This perspective is also relevant for a variety of contexts, given the increasing global diversity of higher education students.

The challenge seems to lie with recognising students as individuals and harnessing their previous experiences so that they are able to create new subject positions and develop as reflexive learners. By drawing on students as a resource in the teaching and learning process, we have learnt a great deal about how they have coped in the past and how to work collectively to help them negotiate boundaries 
and shift practices. The programme has been enriched and changed by their presence and has shifted from focusing on assimilation to a collaborative enterprise which engages with the varying inherent resources in the student body. In this way, the programme has highlighted the need to engage with notions of 'underpreparedness' and 'disadvantage' in a more nuanced, responsive manner. The broader challenge is to embrace these ideals at an institutional level and reframe the learning environment for all students.

\section{References}

Adams, G., M. Berzonsky, and L. Keating .2006. Psychosocial Resources in FirstYear University Students: The Role of Identity Processes and Social Relationships. Journal of Youth and Adolescence 35, no.1: 81-91.

Astin, A.1993. What Matters in College? Four Critical Years Revisited. San Francisco: Jossey-Bass.

Bangeni, B and R. Kapp. 2005. Identities in transition: shifting conceptions of home by black South African university students. African Studies Review 48, no. 3 : 1-19).

Bernstein, B.B. 1990. Class, codes and control. Volume IV, The structuring of pedagogic discourse. London: Routledge.

Bourdieu, P. 1991. Language and Symbolic Power. Cambridge, Massachusetts: Harvard University Press.

Bertram, C. 2003. Moving towards massification: Reflections on a missed-mode teacher education programme. Perspectives in Education, 21 no.2 : 71-82.

Bloch, G. 2009. The Toxic Mix: What's Wrong with South Africa's schools and how to fix it? Cape Town: Tafelberg.

Boughey, C. Academic Development for Improved Efficiency in the Higher Education and Training System in South Africa. Draft 1 to Development Bank of South Africa, 2010.

Bray, R., I. Gooskens, L. Kahn, S. Moses, and J. Seekings. 2010. Growing up in the new South Africa: Childhood and adolescence in post-apartheid. Cape Town: HSRC Press.

Chapman, A., and D. Pyvis. 2006. Dilemmas in the formation of students identity in offshore higher education: a case study in Hong Kong. Educational Review, 58, 3: 291-302.

Christie, H., L.Tett, E. Cree , J. Hounsell, and V. McCune. 2008. A real rollercoaster of confidence and emotions: learning to be a university student. Studies in Higher Education 33,no.5: 567-581

Christie, P. 2008. Changing Schools in South Africa: Opening the Doors of Learning. South Africa: Heinemann.

Coughlan, F. 2006. Access for success. South African Journal of Higher Education 20, no.2: 209-218.

Cummins, J.1996. Negotiating Identities: Education for Empowerment in a Diverse Society Ontario: California Association for Bilingual Education. 
Gee, J. 1990. Social Linguistics and Literacies: Ideology in Discourses. London: Falmer Press.

Haggis, T. 2006. Pedagogies for diversity: retaining critical challenge amidst fears of 'dumbing down'. Studies in Higher Education 31, no. 5: 521-535.

Herrington, A., and M. Curtis. 2000. Persons in Process: Four Stories of Writing and Personal Development in College. Urbana, Illinois: National Council of Teachers of English.

Kapp, R. 2004. 'Reading on the line': An Analysis of Literacy Practices in ESL Classes in a South African Township School. Language and Education, 8, no. 3: $246-263$

Kurfiss, J.G. Critical Thinking: Theory, Research, Practice, and Possibilities. Association for the Study of Higher Education, Washington DC, no. 2.

Institutional Planning Department. 2009.Teaching and Learning Report. University of Cape Town.

Knoblauch, C., and L. Brannon. 1984. Rhetorical Traditions and the Teaching of Writing. Upper Montclair, NJ: Boynton Cook.

Luckett, K., and T. Luckett. 2009. The development of agency in first generation learners in higher education: a social realist analysis. Teaching in Higher Education 14, no.5: 469-481.

Mann, S. 2008. Study, Power and the University. London: McGraw Hill, Society for Research into Higher Education and Open University Press.

MacGregor, J, Cooper, J.L., Smith, K.A, Robinson, P. (Eds). Strategies for Energizing Large Classes: From Small Groups to Learning Communities. New Directions for Teaching and Learning, no.81

Marshall, D, and J. Case. 2010. Rethinking 'disadvantage' in higher education: a paradigmatic case study using narrative analysis. Studies in Higher Education 35, no. 5: 491-504

Mazur, E.1997. Peer Instruction: A User's Manual, Englewood Cliffs, N.J. : Prentice Hall.

Norton, B. 1997. Language, Identity and the Ownership of English. Tesol Quarterly 31, no.3: 409-430.

Ramphele, M. 2002. Steering by the Stars: Being young in South Africa. Cape Town: Tafelberg Publishers.

Reay, D. 2001. Finding or losing yourself? Working-class relationships to education. Journal of Education Policy 16, no.4: 333-346.

Reid, B., L. Archer, and C. Leathwood. 2003. Challenging Cultures? Student Conceptions of 'Belonging' and 'Isolation' at a post-1992 University. Studies in Higher Education 28: 261-277.

Rose, M. 1990. Lives on the Boundary. New York: Penguin.

Scott, I., N.Yeld, and J. Hendry. 2007. Higher Education Monitor No. 6: A case for improving teaching and learning in South African higher education. The Council on Higher Education, Pretoria, South Africa.

Slonimsky, L. \& Shalem, Y. 2004. Pedagogic Responsiveness for Academic Depth. In H. Griesel (Ed.). Curriculum Responsiveness: case studies in higher education (1st ed.) Pretoria: SAUVCA: 81-104.

Springer, L., Stanne, M.E., and Donovan, S.1999. Effects of Small-Group Leaning on Undergraduates in Science, Mathematics, Engineering, and Technology: A Meta-Analysis. Review of Educational Research, 69 (1), 50-80.

Steele, C., 1999. Thin Ice: "Stereotype threat" and Black College students. The Atlantic Monthly 284, no.2: $44-54$. 
Swail, W.S. 2002.Higher Education and the new Demographics: questions for policy. Change, July/August, Vol.34, no 4: 14-23

The South African Institute of Chartered Accounting. 2009. Summarized Group Annual Report, Johannesburg: SAICA

Thomson, R. 2009. Unfolding Lives: Youth, gender and change. Bristol, UK: The Polity Press.

Vygotsky, L. 1978. Mind and Society. Cambridge, MA: Harvard University Press,

Walker, M. 2006. Identity, Learning and agency in higher education. Paper presented at the Interdisciplinary Colloquium on Identity and learning, University of Stellenbosch and University of Cape Town. 